\title{
Loneliness in the elderly in Mexico, challenges to the public policies
}

\author{
María Montero-López Lena*, Diego Luna-Bazaldúa(i) and Laura Ann Shneidman
}

\author{
* Correspondence: monterol@unam. \\ $\mathrm{mx}$ \\ Facultad de Psicología, Universidad \\ Nacional Autónoma de México, Av. \\ Universidad 3004, Edificio D, \\ segundo piso, cubículo 207, Ciudad \\ de México C.P. 04510, Mexico
}

\begin{abstract}
The National Council for the Evaluation of Social Development Policy (CONEVAL 2018) reports that $7.8 \%$ of the population in Mexico is 65 years old or older. Approximately $41.1 \%$ of this population lives in poverty, $34.6 \%$ lives in moderate poverty, and $6.6 \%$ lives in extreme poverty. While previous research has discussed the impact of poverty and loneliness on psychological development and well-being (Mayer, F. David, Ecología económica de lacapacidad cognitiva. 2010; Montero-López Lena, María, Pobreza como Dolor Social, su Impacto sobre la Salud Física y Mental en la vejez, 2018), there is limited research on the association of these variables on the mental health of older adults in Mexico. Thus, this study describes the relationship between loneliness and three variables linked to mental health in a sample of 1126 participants from Mexico City: stress, social support, and family interaction. In addition, the role of participants' genders is considered in the analysis. The results indicate gender differences in the participants' levels of reported stress and loneliness, but no significant differences were observed in their levels of social support and family interaction. Latent variable model results indicate that the negative effect of loneliness on mental health is attenuated when there are family support and social interaction. These results confirm the need to both deepen our understanding of the variables that promote mental health among older adults and to start a rigorous analysis of public policies aimed at the promotion of mental health in this demographic group in Mexico.
\end{abstract}

Keywords: Loneliness, Elderly, Mental health, Mexico, Public policies

\section{Introduction}

Demographic trends of the last decades show that, due to increasing life expectancies, for the first time in Mexican history, family members of four different generations are interacting with each other for a considerable length of time before the oldest family members pass away (CONEVAL 2018; CONAPO 2006). These changes in life expectancy and in generational interaction mean that it is of increasing importance for researchers to identify the relevant variables that positively contribute to good and healthy aging. It is not enough to be able to live longer, as older adults must also have access to a high quality of life, both in physical and in psychosocial terms.

One way to ensure that this occurs is to identify the factors that mitigate feelings of depression that are likely to occur in aging populations and then to target these factors in policy programs. Indeed, depression is now considered one of the main mental health disorders based on worldwide data and indicators (World Health Organization 2018), and

(c) The Author(s). 2019 Open Access This article is distributed under the terms of the Creative Commons Attribution 4.0 International License (http://creativecommons.org/licenses/by/4.0/), which permits unrestricted use, distribution, and reproduction in any medium, provided you give appropriate credit to the original author(s) and the source, provide a link to the Creative Commons license, and indicate if changes were made. 
it is equally likely to affect both younger and older adults. Some theoretical frameworks in psychology have tried to explain the main factors that are specifically linked to depression among older adults. For instance, according to Erickson (1985), depressive episodes occur more frequently in the last stages of life given that older adults have to cope with their aging process, loneliness, and their proximity to death. For older adults, finding meaning in life in their advanced age, as well as dealing with episodes of loneliness while moving naturally to death, is part of a continuous challenge. The components of such struggles at the end of life and the resources to face them tend to occur in diverse systems of social interaction, such as the family, the local community, and the social, cultural, and normative context.

Bronfenbrenner's perspective $(1977,1986)$ is useful in understanding the aging process, as it takes into account these different social systems and contexts. Bronfenbrenner's theory (1986) emphasizes the progressive transactions and adjustments that occur in human development, placing them within an environment in constant change until the end of their lives. The environment is not only the immediate context surrounding the individual, as it also encompasses the social context in which people develop and interact in their everyday lives.

Bronfenbrenner (1977) defined the term "system" as the changing interaction between the subject and the environment in which he develops; there are five hierarchical ecological systems that are distinguished from one another based on the proximity and immediate influence that they have on the individual: the microsystem, the mesosystem, the exosystem, the macrosystem, and the chronosystem. Of the five ecological systems, in this study, we emphasize the interactions that occur at the microsystem level, given this system's direct impact on the psychosocial functioning of older adults; in this regard, the microsystem refers to the reciprocal interactions between the individual and his or her most immediate environment.

Although Bronfenbrenner's theory emphasizes childhood, it is possible to consider its relevance to understand other stages of development, such as advanced age. For instance, the microsystem may involve the direct and reciprocal social interactions between an older adult and his or her primary caregivers at home or in a nursing home. These interactions will have an impact on the perception of family and social support, loneliness, and stress of the older adult. In fact, prior research has confirmed that the frequency and quality of micro-level interactions that older adults establish with others in their physical and social environments have an impact on their mental health and emotional well-being (Bekhet and Zauszniewski 2012).

Thus, it becomes relevant that social researchers continue to inquire about the elements in the different hierarchies of the socio-ecological environment that are relevant for the promotion of the well-being and quality of life of older adults. The goal of this paper is to consider the factors that relate to mental health in older adults by specifically asking how micro-level interactions might contribute to or attenuate the perception of loneliness and stress in an aging population.

\section{Variables linked to mental health in older adults Loneliness}

Loneliness is considered an essentially subjective and potentially stressful phenomenon produced from either real or perceived affective deficiencies (Montero-López Lena 
1999). It should be noted that although physical isolation is associated with loneliness, they are not the same phenomena. Insofar as isolation has a physical correlate, loneliness is an essentially subjective experience (Montero-López Lena and Sánchez-Sosa 2001). In Mexico, the study of loneliness is relatively new; only recently has it been recognized that loneliness is a phenomenon that may impact the mental health of those who experience it (Montero-López Lena 2016b). At the end of 2017, it was reported that approximately $43 \%$ of older adults in Mexico City were living in conditions of isolation and vulnerability (INEGI 2018).

With regard to psychological research on loneliness in Mexico, Montero-López Lena (2003) analyzed the objective and subjective meaning that adolescents and adults give to the concept of "loneliness." The results of this study indicate that loneliness was frequently defined as an unpleasant experience. It was also found, however, that as people get older, they tend to apply positive terms to loneliness: self-knowledge, tranquility, and transcendence, for example. These results suggest that there are both personal and contextual components that may shape the experience of loneliness as either something negative or positive. Research conducted in Mexico shows that there might be a link between loneliness and chronic conditions such as renal failure, diabetes, and hypertension among older adults (Rivera-Ledesma et al. 2012; Montero-López Lena 2018). Both women and men in the latter stages of their lives tend to perceive loneliness as a reaction to the perception of stress (Montero-López Lena and DíazCastillo 2017).

Consistently over the last few decades, sex differences have been noted in the frequency of the reported experience of loneliness in English-speaking countries (Borys and Pelman 1985; Lau et al. 1992). In Mexico, it has also been documented that women tend to cognitively link the meaning of loneliness with more semantic concepts (Montero-López Lena 1993), and they also tend to perceive experiences of loneliness more frequently as compared to men (Guevara and Montero-López Lena 1994).

\section{Stress}

The perception of stress is a psychological process associated with specific external and/or internal demands commonly evaluated as disproportionate given the cognitive, emotional, and behavioral resources available to the individual (Lazarus and Folkman 1986). The perception of stress among older adults is commonly considered an indicator of mental health. When older adults are embedded within a physical and social context that provides security and stability, these individuals tend to perceive lower stress in their environment; by contrast, this perception of stress increases when older adults feel vulnerable or at risk.

In this sense, Marshall et al. (2015) mention that frequent exposure to stressful situations can negatively affect the mental health of older adults, specifically obstructing their working memory. In a similar manner, Liu et al. (2016) reported that after older adults have lost their cognitive faculties, their satisfaction with life functions as a mediator between their perceived stress and the severity of their depression. The frequent experience of stress, regardless of its origin, may harm older adults' social interactions with other people, especially their families (Cutrona et al. 1986).

\section{Quality of family interaction}

Family interaction is a psychosocial factor that tends to diminish the perception of stress. Bronfenbrenner (1986) documented how the quality of the microsystem linked 
to the family context constitutes a protective factor for the efficient development of the individual. This security in the family microsystem is particularly critical for the optimal functioning of older adults, due to the potential inverse relationship between the ability to adapt to the environment and the social dependence that humans have with their close relatives. In this way, positive family interaction is a protective factor for the emotional and mental health of older adults. If family interaction is inadequate, harm is done to the adaptive ability of older family members. By contrast, when family interaction is present and successfully provides older adults with a stable and protective environment, then the physical and psychological transition into the last phases of life will be less stressful, helping older adults to potentially live in a more dignified way.

In this regard, prior research has documented that family interaction is an important factor in the prediction of the experience of loneliness among older adults in Mexico (Montero-López Lena 2016a). Similarly, Marin and Huber (2011) reported that older adults' perceptions of their own families operated as a protective factor against self-reported anxiety. Overall, family interaction in combination with social support may enhance the ability of older adults to adapt to their environment, thus acting as a protective factor of their mental health.

The quality of family and social interactions is a relevant factor that may either intensify or alleviate the experience of loneliness and stress in older adults (Cutrona et al. 1986; Krause 1987). Therefore, it is reasonable to assume that the social support perceived by older adults is essential in the promotion of their mental health.

\section{Social support}

Social support is regarded as a multidimensional construct that has two basic components: a structural component that refers to the extension of social networks and a functional or expressive component that represents the type of support received. Meanwhile, social support can either be emotional, when an individual receives encouragement from friends or family during a life crisis; instrumental, when he or she receives physical assistance in accomplishing a specific task; or informative, when he or she receives expert advice on a particular topic. According to Da Silva Pedro et al. (2008), social support is understood as any type of systematic support offered by groups of people that has positive effects on the recipient.

Former research focused on social support among older adults has shown that insufficient social networks during the later stages of life may lead to higher disability and mortality rates (Andrew et al. 2008; Holt-Lunstad et al. 2010).

\section{Public policies for older adults in Mexico}

Although psychological variables contribute to the well-being of older adults, the context in which they develop and socially interact may promote or reduce mental health. In this regard, it is reasonable that public policies function at different social levels as tools to regulate and promote the well-being of the populace. Specifically, most of the public policies for the care of older adults that have been implemented in Mexico have been adopted from abroad, with mixed efficiency in their implementation and results.

In terms of public policies for the care of older adults, the United Nations has been analyzing the state of the aging process across countries worldwide (United Nations 
2016). Since 1982, the year that the First World Assembly on aging was held, the assembled countries solemnly reaffirmed their conviction that the fundamental rights enshrined in the Universal Declaration of Human Rights must be fully applied to older adults. Consequently, public policy is required to consider older adults as an integral part of society who may enjoy, within their families and communities, a full, healthy, safe, and satisfying life.

On December 16, 1991, the United Nations Principles for Older Persons were adopted, and governments were encouraged to incorporate these principles into their national programs in order to establish conditions that protect and respect older adults (United Nations 2016). Among the actions to be promoted by these principles, five stood out: (1) independence, emphasizing the providing of older adults with greater access to adequate education and training programs, food, water, housing, clothing, and safe environments, as well as allowing them to reside at home (when possible); (2) participation, calling for older adults to remain integrated in society via their participation in the formulation and application of public policies that affect their well-being, as well as their ability to share knowledge with younger generations; (3) care, focusing on the care and protection of older people on behalf of their families and communities, including access to health, social, legal, protection, and rehabilitation services; (4) selfrealization, aiming at the promotion of opportunities for the full development of older adults, including access to educational, cultural, spiritual, and recreational resources; and (5) dignity, an action implying that older people have the right to live with security and dignity, free from exploitation, physical and mental abuse, and that they must receive dignified treatment regardless of age, sex, race, disability, or economic condition.

Regarding public policies focused on mental health, it is also relevant to emphasize the role of public policies aimed at supporting older adults. These policies taken from abroad have been designed and implemented in an inconsistent manner in Mexico. The first government policies concerned with the care of older adults date from 1979, when the National Institute of the Elderly (INSEN) was created. This institute was renamed as the National Institute for Older Adults (INAPAM) in 2002. This institute serves Mexican adults over 60 years old nationwide, coordinating public policies regarding social and human development and aimed at producing changes in society to enhance the support, care, and respect for older people.

Specifically, Mexico City's Institute for the Care of the Elderly (IAAM 2017) was created in 2017. Its purpose is to support the well-being of older adults and to promote social awareness on topics related to the aging process. This institute aims to encourage a change in attitudes within the general population, such a move towards considering older people as socially active citizens and framing the aging process as a normal part of the life cycle.

Current government support programs for older adults in Mexico, however, are narrow in their scope and objectives. For instance, assistance initiatives consisting of cash payouts to older adults equivalent to $\$ 67.00$ USD per month are insufficient to cover the health expenses that older people face (Secretaria de Bienestar 2019).

Healthcare is also a common challenge faced by older adults in Mexico. Citizens affiliated with one of the two main health institutions, the geriatric care units run by ISSSTE (2002) and the Center of Social Care for the Health of Older Adults run by IMSS (2012), benefit from support programs focused on physical activity and 
recreation. The coverage of these programs for older people, however, is still limited. Current challenges in public health policies for older adults involve the planning and implementation of comprehensive health interventions tailored for different social groups, as well as mechanisms to provide healthcare for older people not supported by either ISSSTE or IMSS. In this regard, programs that seek to promote dignified aging must identify the particularities of this developmental process both in terms of the psychosocial characteristics of the aging population as well as their sociocultural contexts.

The development and improvement of public policies for older adults require the collaborative work of experts from different areas of expertise, as well as advancements in knowledge that may guide current efforts towards evidence-based interventions. In congruence with these ideas, this study proposes the empirical verification of a multidimensional model that accounts for variables linked to mental health among older adults. Based on a theoretical background, research on loneliness is gaining relevance due to its impact on mental health. Still, it is important to understand the impact that loneliness may have on additional psychosocial variables such as the perception of stress, family interaction, and social support. Thus, the empirical corroboration of a descriptive model that identifies the direction and magnitude of the relationships among these variables is the main objective of this study.

\section{Method}

Based on the theoretical framework and former research, four hypotheses were empirically tested:

1. Loneliness has a positive and significant correlation with stress.

2. Social support has a positive and significant correlation with family interaction.

3. Social support and family interaction have negative and significant correlations with both loneliness and stress.

4. Women and men show differences in their reported levels of loneliness, stress, family interaction, and social support.

\section{Participants}

The sample for this study consisted of 1126 participants living in Mexico City, 749 women and 377 men. The average age of the participants was 73 years old, ranging from 60 to 97 years old. In order to participate in the study, the participants had to be able to read and write, and they had to demonstrate a sufficient cognitive capacity to answer the questions included in the questionnaires. Participants reported that, on average, 3 people lived in their homes. However, approximately $15 \%$ of those in the sample lived alone, almost $30 \%$ of the older adults in the sample reported living with only one other person at home, and around $55 \%$ of the participants indicated that they were living with two or more people at home.

\section{Variables and measures}

The "loneliness" variable was measured using the IMSOL-AM questionnaire which includes 20 items in Likert format grouped into two theoretical components linked to loneliness: personal alienation and family alienation (Montero-López Lena and Rivera-Ledesma 2009). This 
instrument was developed in Mexico and presents evidence of validity and high internal consistency. Some items included in this scale include "Do you feel lonely?," "Do you feel helpless?," and "Do you feel rejected?"

The "perception of stress" variable was measured using a scale developed by Cohen et al. (1983) and adapted in Mexico by Montero-López Lena (2016a). The questionnaire includes 14 Likert-scale items with levels of internal consistency. Examples of items include "Have you felt that the difficulties increased to the point that you could not solve them?," "Have you felt anxious?," and "Have you been feeling angry because of things that were out of your control?"

In this study, mental health is operationalized based on loneliness and the perception of stress. Former research has found that loneliness is highly related to the mental health and psychosocial well-being of older adults (Alpass and Neville 2003). Meanwhile, it is recognized that loneliness has a pervasive effect on indicators of mental health such as depression, anxiety, and stress (Bekhet and Zauszniewski 2012). In this regard, a poorer mental health is found when older adults report higher levels of loneliness and stress in their lives.

The "family interaction" variable was measured using the questionnaire developed by Montero-López Lena and Evans (2008), which consists of five Likert-scale items measuring a single latent factor. This questionnaire also has high levels of reliability. Some items measuring family interaction include "How often do you tell someone in your family how much you love him/her?" and "How often do you observe what happens in your family and offer your advice?"

The "social support" variable was measured using the Social Support Scale (ESSAM), which was originally developed by Tagaya et al. (2000). This scale was translated and adapted in Mexico by Rivera-Ledesma et al. (2013). The scale consists of eight items that measure a single factor that explains $60.7 \%$ of the item variance. The Social Support Scale also has high internal consistency. Some of the items measuring social support include "Do you have someone who takes care of you when you get sick?," "Do you have someone who makes you feel calm?," and "Do you have someone to ask for advice about your concerns?"

\section{Data collection}

A team of 13 undergraduate research assistants was trained to collect data from the participants. The training lasted a week and consisted in the acquisition of skills to establish rapport with participants and to uniformly apply the questionnaires. The research assistants went to hospitals, parks, cafeterias, restaurants, and churches in Mexico City to collect information from people who voluntarily agreed to participate following informed consent.

The application of each questionnaire lasted, on average, $30 \mathrm{~min}$. During the administration of the questionnaires, the interviewers were attentive in ensuring that the participants answered each and every one of the questions independently. After the completion of the surveys, they verified that the information was complete and gave each participant a thank-you card. The card also included the contact information of the UNAM School of Psychology in case the participants were interested in knowing the results of the study. 


\section{Results}

Descriptive statistics and scale reliability

Internal consistency measures were estimated for each questionnaire using Cronbach's alpha statistic. Results indicated that the loneliness scale presented a reliability level $\alpha=0.96$, the stress perception scale yielded a reliability coefficient of $\alpha=0.86$, the social support scale presented a reliability estimate of $\alpha=0.89$, and the family interaction questionnaire produced a reliability level of $\alpha=0.79$. Table 1 summarizes item statistics for each scale in terms of the mean, standard deviation, and item-total correlation. On average, participants tended to score higher on items measuring family interaction and social support compared to items linked to stress and loneliness. The internal consistency among items measuring the same construct was corroborated based on the positive item-total score correlations obtained in each of the four scales.

\section{Latent variable model}

As represented in Fig. 1, a latent variable model was estimated to test the research hypotheses. The model proposes relationships among four latent variables measuring loneliness, stress, social support, and family interaction. Each latent variable is measured by the corresponding items of the scales described in the "Method" section. Results for the latent variable model are summarized in Tables 2 and 3. Model fit statistics indicate that the model fits the data: $\chi^{2}=2123.918(\mathrm{df}=773, p$ value $<0.001)$, $\mathrm{CFI}=0.996, \mathrm{TLI}=0.995, \mathrm{RMSEA}=0.039$ with $90 \%$ confidence intervals $(0.037,0.041)$, and SRMR $=0.042$.

Table 2 includes information for the measurement component of the model: standardized factor loadings estimates, their corresponding standard errors, their $p$ values, and the estimated residuals for each item. The factor loadings and $p$ values reported in Table 2 show that all items present a positive significant relationship with their corresponding unidimensional latent factor. No factor loading was smaller than 0.3 in absolute value, thus implying that the measurement component of the latent variable model adequately represents the relationships between observed and latent variables.

It is important to highlight that while previous research done by Montero-López Lena and Rivera-Ledesma (2009) on the loneliness questionnaire reported two highly correlated latent factors-personal alienation and family alienation-here we are proposing a unidimensional model for loneliness with the aim of maintaining parsimony. Moreover, while not reported here for the sake of brevity, a unidimensional model yielded more favorable relative fit statistics when compared to a model with two latent correlated factors.

Table 3 includes estimates for the structural component of the model: correlation estimates among the latent variables in the model, their standard errors, and their $p$ values. The directions and significance of all correlations empirically support the hypotheses of the study: loneliness and stress are positively related with each other, as are social support and family interaction, and all other correlations among the latent variables are negative.

\section{Graded response model}

Given that the loneliness questionnaire showed an adequate fit to a unidimensional factor analysis model and high item-total score correlations, additional analyses were done 
Table 1 Item Statistics: Mean, Standard Deviation and Item-total Correlation

\begin{tabular}{|c|c|c|c|}
\hline & Mean & SD & Item-total correlation \\
\hline \multicolumn{4}{|l|}{ Loneliness } \\
\hline Item 1 & 1.504 & 1.4 & 0.522 \\
\hline Item 2 & 0.785 & 1.028 & 0.723 \\
\hline Item 3 & 1.137 & 1.217 & 0.676 \\
\hline Item 4 & 0.861 & 1.11 & 0.767 \\
\hline Item 5 & 0.999 & 1.178 & 0.756 \\
\hline Item 6 & 0.829 & 1.159 & 0.79 \\
\hline Item 7 & 0.907 & 1.173 & 0.705 \\
\hline Item 8 & 0.867 & 1.148 & 0.782 \\
\hline Item 9 & 1.008 & 1.224 & 0.809 \\
\hline Item 10 & 0.847 & 1.183 & 0.789 \\
\hline Item 11 & 0.617 & 1.075 & 0.816 \\
\hline Item 12 & 0.667 & 1.076 & 0.813 \\
\hline Item 13 & 1.111 & 1.252 & 0.771 \\
\hline Item 14 & 0.837 & 1.181 & 0.679 \\
\hline Item 15 & 1.042 & 1.174 & 0.699 \\
\hline Item 16 & 0.677 & 1.026 & 0.711 \\
\hline Item 17 & 0.576 & 1.04 & 0.789 \\
\hline Item 18 & 0.77 & 1.148 & 0.789 \\
\hline Item 19 & 0.868 & 1.118 & 0.748 \\
\hline Item 20 & 1.188 & 1.131 & 0.71 \\
\hline \multicolumn{4}{|c|}{ Social support } \\
\hline Item 1 & 1.936 & 1.08 & 0.686 \\
\hline Item 2 & 2.336 & 0.925 & 0.786 \\
\hline Item 3 & 2.555 & 0.729 & 0.77 \\
\hline Item 4 & 2.381 & 0.864 & 0.78 \\
\hline Item 5 & 1.976 & 1.103 & 0.707 \\
\hline Item 6 & 2.341 & 0.906 & 0.808 \\
\hline Item 7 & 2.22 & 0.949 & 0.796 \\
\hline Item 8 & 2.33 & 0.958 & 0.778 \\
\hline \multicolumn{4}{|l|}{ Stress } \\
\hline Item 1 & 1.316 & 1.17 & 0.656 \\
\hline Item 2 & 1.306 & 1.208 & 0.7 \\
\hline Item 3 & 1.662 & 1.187 & 0.705 \\
\hline Item 4 & 1.189 & 1.099 & 0.732 \\
\hline Item 5 & 1.429 & 1.136 & 0.7 \\
\hline Item 6 & 1.189 & 1.163 & 0.727 \\
\hline Item 7 & 1.388 & 1.13 & 0.743 \\
\hline Item 8 & 1.17 & 1.182 & 0.751 \\
\hline \multicolumn{4}{|c|}{ Family interaction } \\
\hline Item 1 & 2.292 & 1.131 & 0.677 \\
\hline Item 2 & 3.152 & 1.055 & 0.709 \\
\hline Item 3 & 2.761 & 1.098 & 0.761 \\
\hline Item 4 & 2.679 & 1.184 & 0.767 \\
\hline Item 5 & 2.976 & 1.173 & 0.782 \\
\hline
\end{tabular}

Note: SD refers to the item standard deviation 


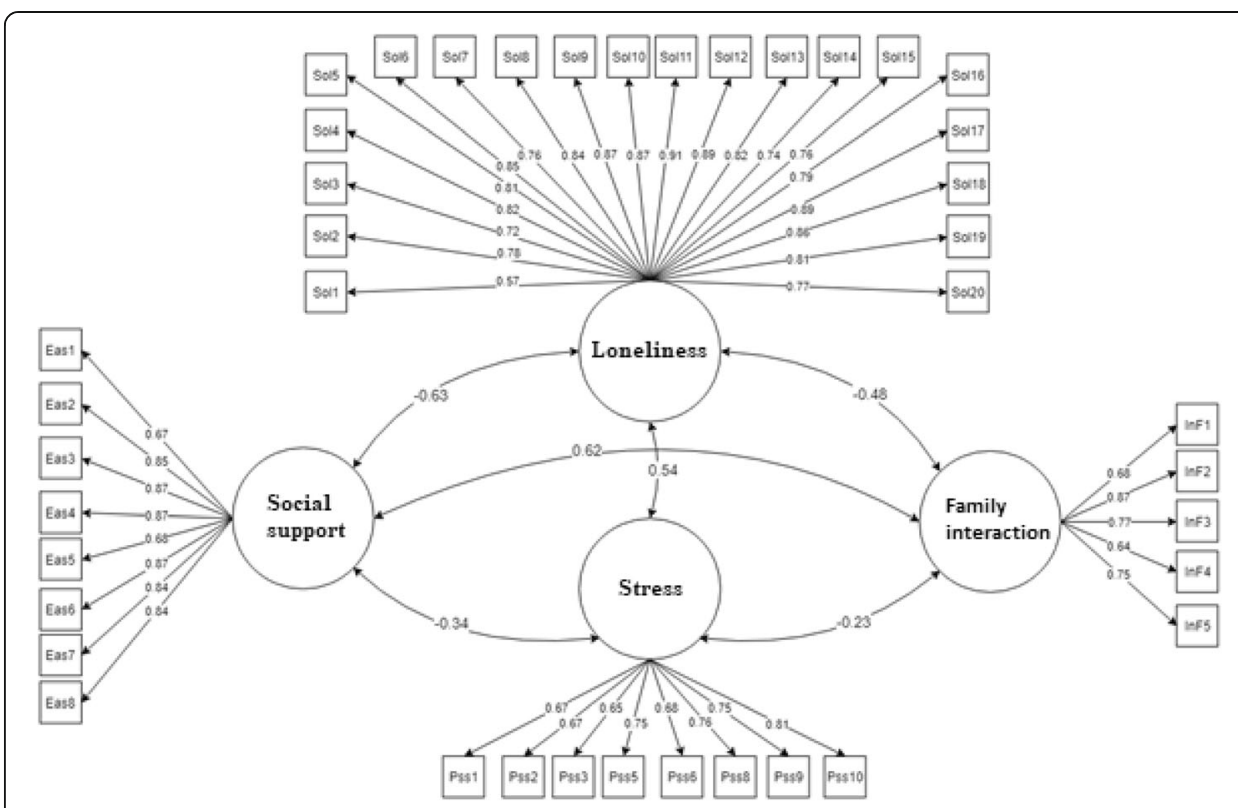

Fig. 1 Latent variable model for the relationship between loneliness, social support, family interaction, and stress

using the logistic version of the unconstrained graded response model (Samejima 1997). As shown in Table 4, most of the items exhibit a high threshold in the change from the first category to the second category (i.e., parameter $\beta_{1}$ ), which from a psychological perspective means that participants must perceive a considerable amount of loneliness in their personal lives before selecting the item option "almost never" over the option "never." In addition, the item discrimination parameter estimate was above the unity value for all items, which indicates that the items are good at differentiating between participants with high and low levels of perceived loneliness.

\section{Differences by sex}

Several $t$ tests were estimated to compare average levels of loneliness, the perception of stress, family interaction, and social support between female and male participants. Table 4 shows the means by gender, as well as the $t$ test and Levene's test statistics. Results indicate that there are statistically significant differences between women and men in their reported levels of loneliness and stress, but not in their reported levels of social support and family interaction. Welch's correction was conducted in the $t$ test when the homogeneity of variance assumption was not satisfied (see Table 5).

\section{Discussion}

The objective of this study was to propose a model that could describe the directions of the relationships between loneliness, the perception of stress, family interaction, and social support in a sample of older adults in Mexico. Likewise, public policies linked to the well-being of older adults were analyzed. The results confirmed three out of the four hypotheses. First, loneliness had a positive correlation with the perception of stress. Second, family interaction and social support presented a positive correlation. Third, all other correlations among the latent variables representing the constructs 
Table 2 Factor loadings and residuals for the observed variables

\begin{tabular}{|c|c|c|c|}
\hline & Loading (SE) & $p$ value & Residual \\
\hline \multicolumn{4}{|l|}{ Loneliness } \\
\hline Item 1 & $0.575(0.007)$ & $<0.001$ & 0.669 \\
\hline Item 2 & $0.782(0.006)$ & $<0.001$ & 0.388 \\
\hline Item 3 & $0.722(0.006)$ & $<0.001$ & 0.479 \\
\hline Item 4 & $0.818(0.005)$ & $<0.001$ & 0.331 \\
\hline Item 5 & $0.811(0.005)$ & $<0.001$ & 0.343 \\
\hline Item 6 & $0.855(0.005)$ & $<0.001$ & 0.27 \\
\hline Item 7 & $0.761(0.006)$ & $<0.001$ & 0.421 \\
\hline Item 8 & $0.84(0.005)$ & $<0.001$ & 0.295 \\
\hline Item 9 & $0.867(0.005)$ & $<0.001$ & 0.248 \\
\hline Item 10 & $0.866(0.005)$ & $<0.001$ & 0.251 \\
\hline Item 11 & $0.912(0.005)$ & $<0.001$ & 0.168 \\
\hline Item 12 & $0.893(0.005)$ & $<0.001$ & 0.203 \\
\hline Item 13 & $0.822(0.005)$ & $<0.001$ & 0.324 \\
\hline Item 14 & $0.743(0.006)$ & $<0.001$ & 0.448 \\
\hline Item 15 & $0.757(0.006)$ & $<0.001$ & 0.427 \\
\hline Item 16 & $0.789(0.006)$ & $<0.001$ & 0.377 \\
\hline Item 17 & $0.892(0.005)$ & $<0.001$ & 0.205 \\
\hline Item 18 & $0.856(0.005)$ & $<0.001$ & 0.267 \\
\hline Item 19 & $0.81(0.006)$ & $<0.001$ & 0.343 \\
\hline Item 20 & $0.772(0.006)$ & $<0.001$ & 0.404 \\
\hline \multicolumn{4}{|c|}{ Social support } \\
\hline Item 1 & $0.67(0.009)$ & $<0.001$ & 0.551 \\
\hline Item 2 & $0.849(0.008)$ & $<0.001$ & 0.279 \\
\hline Item 3 & $0.872(0.008)$ & $<0.001$ & 0.239 \\
\hline Item 4 & $0.87(0.007)$ & $<0.001$ & 0.243 \\
\hline Item 5 & $0.675(0.009)$ & $<0.001$ & 0.545 \\
\hline Item 6 & $0.874(0.007)$ & $<0.001$ & 0.237 \\
\hline Item 7 & $0.838(0.007)$ & $<0.001$ & 0.297 \\
\hline Item 8 & $0.837(0.008)$ & $<0.001$ & 0.3 \\
\hline \multicolumn{4}{|l|}{ Stress } \\
\hline Item 1 & $0.667(0.01)$ & $<0.001$ & 0.555 \\
\hline Item 2 & $0.673(0.01)$ & $<0.001$ & 0.548 \\
\hline Item 3 & $0.653(0.01)$ & $<0.001$ & 0.573 \\
\hline Item 4 & $0.749(0.009)$ & $<0.001$ & 0.439 \\
\hline Item 5 & $0.681(0.009)$ & $<0.001$ & 0.536 \\
\hline Item 6 & $0.758(0.009)$ & $<0.001$ & 0.426 \\
\hline Item 7 & $0.751(0.009)$ & $<0.001$ & 0.436 \\
\hline Item 8 & $0.811(0.009)$ & $<0.001$ & 0.342 \\
\hline \multicolumn{4}{|c|}{ Family interaction } \\
\hline Item 1 & $0.682(0.012)$ & $<0.001$ & 0.535 \\
\hline Item 2 & $0.87(0.013)$ & $<0.001$ & 0.243 \\
\hline Item 3 & $0.765(0.012)$ & $<0.001$ & 0.414 \\
\hline Item 4 & $0.644(0.011)$ & $<0.001$ & 0.585 \\
\hline Item 5 & $0.752(0.012)$ & $<0.001$ & 0.435 \\
\hline
\end{tabular}

Note: SE refers to the standard errors of the factor loadings 
Table 3 Correlations among latent variables

\begin{tabular}{lllr}
\hline Variables & & Correlation (SE) & $p$ value \\
\hline Loneliness & Social support & $-0.625(0.004)$ & $<0.001$ \\
Loneliness & Family interaction & $-0.478(0.007)$ & $<0.001$ \\
Loneliness & Stress & $0.542(0.005)$ & $<0.001$ \\
Social support & Family interaction & $0.616(0.01)$ & $<0.001$ \\
Social support & Stress & $-0.34(0.008)$ & $<0.001$ \\
Family interaction & Stress & $-0.229(0.01)$ & $<0.001$ \\
\hline
\end{tabular}

Note: SE refers to the standard errors of the correlations

were negative. Finally, the data partially support the fourth hypothesis given that there were statistical differences between women and men in their reported levels of loneliness and stress, but not in the variables for social support and family interaction. Overall, these results show that loneliness is a relevant experience for older people, and it can be considered as a factor linked to their mental health. Moreover, positive family interaction and social support may alleviate the negative consequences of feeling lonely.

The empirical evidence confirms that loneliness is linked to the mental health of older adults in Mexico based on its positive and significant correlation with the perception of stress. This finding is relevant because there is evidence that prolonged exposure to stressors negatively contributes to the mental health of older adults (Marshall et al. 2015). In particular, chronic stress has a negative effect on the self-regulatory capacity (Lipina 2016), and this cognitive process is crucial among older adults given its

Table 4 Parameter estimates of the graded response model on loneliness questionnaire

\begin{tabular}{|c|c|c|c|c|c|}
\hline & $\beta_{1}$ & $\beta_{2}$ & $\beta_{3}$ & $\beta_{4}$ & $a$ \\
\hline Item 1 & -0.559 & 0.208 & 1.698 & 2.476 & 1.029 \\
\hline Item 2 & 0.665 & 2.045 & 4.833 & 6.157 & 2.071 \\
\hline Item 3 & -0.117 & 0.830 & 3.111 & 4.295 & 1.648 \\
\hline Item 4 & 0.640 & 2.018 & 4.562 & 6.131 & 2.337 \\
\hline Item 5 & 0.276 & 1.380 & 4.139 & 5.290 & 2.163 \\
\hline Item 6 & 1.020 & 2.432 & 4.726 & 6.021 & 2.563 \\
\hline Item 7 & 0.563 & 1.475 & 3.582 & 4.680 & 1.752 \\
\hline Item 8 & 0.853 & 1.937 & 4.718 & 5.962 & 2.481 \\
\hline Item 9 & 0.524 & 1.711 & 4.588 & 5.809 & 2.717 \\
\hline Item 10 & 1.107 & 2.294 & 4.601 & 5.908 & 2.586 \\
\hline Item 11 & 2.583 & 4.195 & 6.597 & 8.349 & 3.617 \\
\hline Item 12 & 2.043 & 3.328 & 6.162 & 7.605 & 3.201 \\
\hline Item 13 & 0.101 & 1.203 & 3.535 & 4.883 & 2.165 \\
\hline Item 14 & 0.910 & 1.782 & 3.642 & 4.705 & 1.803 \\
\hline Item 15 & 0.100 & 0.969 & 3.460 & 4.801 & 1.719 \\
\hline Item 16 & 1.236 & 2.370 & 4.674 & 6.020 & 2.040 \\
\hline Item 17 & 2.471 & 3.624 & 6.085 & 7.486 & 3.063 \\
\hline Item 18 & 1.399 & 2.572 & 4.866 & 6.089 & 2.622 \\
\hline Item 19 & 0.639 & 1.774 & 4.365 & 5.642 & 2.104 \\
\hline Item 20 & -0.483 & 0.613 & 3.829 & 4.937 & 1.839 \\
\hline
\end{tabular}

Note: The four $\beta$ 's refer to the category-boundary difficulty parameter estimates, and $a$ refers to the item discrimination parameter estimate 
Table $\mathbf{5} t$ test and Levene's test statistics by gender

\begin{tabular}{llllllll}
\hline Variable & Mean male & Mean female & $t$ & $\mathrm{df}$ & $p$ value & Levene & $p$ value \\
\hline Loneliness & 16.525 & 18.886 & -2.198 & 1124 & 0.028 & 2.102 & 0.147 \\
Stress & 9.604 & 11.173 & -3.773 & 1124 & $<0.001$ & 5.538 & 0.018 \\
Social support & 18.249 & 17.987 & 0.723 & 1124 & 0.469 & 0.028 & 0.867 \\
Family interaction & 13.960 & 13.809 & 0.573 & 1124 & 0.566 & 0.902 & 0.342 \\
\hline
\end{tabular}

Note: $t$ refers to the $t$ test statistic, and df refers to the degrees of freedom. $P$-values smaller than 0.05 are italicized in the table

impact on factors such as attention, working memory, and decision-making. Therefore, an ongoing experience of loneliness might lead to an emotional and mental health detriment during the later stages of life. In this regard, an important contribution of this study is to emphasize how the perception of loneliness as a stressor is frequently ignored in studies focused on older people. Moreover, a potential way to reduce the negative effects of loneliness among older adults is to identify the sources of their perceived deprivation of affection and, consequently, tailor specific interventions to compensate for that lack of positive affection in their social environment.

Results confirm that the perception of stress is a variable that enhances the pernicious effects of loneliness, particularly in the last stages of life. Similar results have been reported in other regions of the world (Marshall et al. 2015, Liu et al. 2016). In order to work with older people experiencing social isolation, it is necessary to identify strategic variables that lessen this negative relationship between the perception of stress and the experience of loneliness; in that regard, this study considers social support and family interaction as protective factors. The results confirmed previous findings on the important protective role that family interaction plays against anxiety and the experience of loneliness in older adults (Marin and Huber 2011). In a similar manner, positive social support has a protective effect on older people (Andrew et al. 2008; Holt-Lunstad et al. 2010). Still, further research needs to be done in order to understand the critical role of the social network and its extension as a protective factor that enhances the quality of life of older adults.

We believe that a clinical perspective still prevails in public policies aimed at older people in Mexico. Although the physical health of older people is obviously an important aspect in the support of their well-being, it is also relevant to take into account their reactions to affection and the social context in which they develop. With respect to the physical and mental care of the elderly, there are two essential sources of care for them in Mexico: first, their immediate and extended family, and second, health professionals, although the services of such professionals are not accessible to older adults who lack resources or who are covered by certain types of public or private health insurance. Despite the proliferation of studies on general care for the elderly, the challenge is to develop strategies that improve the quality of their care, while reducing both the stress on the caregivers and the costs of managing their care (Zarit and Reamy 2013). Thus, public policies should promote three specific areas of research and evaluation for interventions. First, tailored intervention methodologies for older adults that take into account their family context should be developed. Second, indicators to evaluate current and future interventions in order to determine their effectiveness and efficiency should be developed. And third, both community and institutional intervention models that are sensitive to the cultural particularities of older adults should be developed. In this regard, the ecological systems framework proposed by Bronfenbrenner 
(1979) serves as a useful theoretical framework for the development and evaluation of tailored interventions and policies at the different ecological levels; for instance, as part of the macrosystem, this framework could be used in future research to analyze the impact of healthcare systems on the mental health and well-being of older adults.

One of the biggest challenges in the arena of public policy in Mexico is the right to welfare, which is especially relevant for the elderly. They not only face the decline of their physical health, but must also endure social and economic difficulties. In this regard, pensions are one of the major policy tools available for the social and economic safeguarding of the elderly. More evaluations, however, are required to understand how pensions and cash transfer programs may affect older citizens in terms of their subjective well-being (Kim 2013). In the context of Mexico, there is a potential area of research focused on understanding the role of pensions and their economic, social, and psychological impact on their beneficiaries and their families. While pensions should represent a repayment for work done over many years, in Mexico, they are instead a factor linked to poverty.

Thus, in order to promote the well-being of older adults, it is important to carry out additional research to identify additional variables that might promote positive coping strategies and reduce negative stressors. Given these results and their implications, and with an emphasis on the physical and psychological well-being of older adults, the following guidelines should be incorporated into the public policy agenda for older people. First, diversity should be considered with respect to the aging process. While aging is a universal process, it is not uniform. Cognitive, emotional, and social functions change over time depending on the context in which older adults develop and interact with others. Thus, it would be desirable if public policies emphasized the promotion of agency rather than the granting of palliative care. Second, the idea of advanced age as another stage of development should be promoted. Public policies should aim to transform the societal prejudices regarding advanced age and promote it as another stage of development in life. A key element to promote this change in attitude is to highlight the benefits that occur in life as people get older. Third, intergenerational communication and interaction should be encouraged. It is essential that young people understand firsthand the experience of aging. Future generations will also face social and economic challenges when they become older, so it is important that they have knowledge regarding life's transitions passed on from the previous generations. This intergenerational transmission of knowledge has the potential to positively impact aging outcomes by enabling younger generations to better plan for the future.

\section{Conclusions}

This study is innovative in Mexico for three reasons. First, it proposes the identification and evaluation of relevant psychosocial variables linked to subsystems of human development (Bronfenbrenner 1977, 1979, 1986), which allows us to empirically verify associations and interactions of factors from different subsystems that impact the mental health of older adults. We expect that this psychosocial empirical analysis supports a perspective that considers aging as a dynamic process in which positive social interactions can have a positive effect on mental health. At the same time, the empirical evidence and focus of this study emphasize the relevance of the social-ecology approach for the understanding of complex psychological and social interactions in the last stages of life. 
Second, each step of this research project was carefully and systematically carried out to lessen potential threats that could invalidate our results. The selection and measurement of the variables were carried out in accordance with the social-ecology approach, considering variables that occur in the microsystem. Finally, this study is a pioneer in Mexico for its conceptual consistency. Namely, previously documented relationships were confirmed, such as the positive relationship between loneliness and stress and the fact that women report a more solitary experience than men (Guevara and MonteroLópez Lena 1994; Montero-López Lena 1993). In Mexican culture, family interaction and social support are two psychosocial variables that maintain and support the emotional stability of older people, and the lack of differences by gender detected in the corresponding scores is evidence of this aspect.

Regarding the analysis of public policies, it is evident that there is a lack of psychological elements linked to mental health in the current public programs aimed at caring for older adults. This represents a large oversight, since these programs are intended to promote the well-being of this sociodemographic group. Thus, more work has to be done to inform government decision-makers about the relevance of mental health for older adults and the psychosocial factors that support it.

It is clear that the efforts to promote the physical, mental, and social health of the elderly must be coordinated, multidisciplinary, and implemented from the micro to the macro level. This study is an example that shows it is possible to use scientific research to advocate for public policies that better promote the mental health and well-being of older adults in Mexico.

\begin{abstract}
Abbreviations
CFI: Confirmatory fit index; CONAPO: Consejo Nacional de Población [National Population Council]; CONEVAL: Consejo Nacional de Evaluación de la Política de Desarrollo Social [National Council for the Evaluation of Social Development Policy]; ESS-AM: Escala de Apoyo Social [Social Support Scale]; IAAM: Instituto para la Atención de los Adultos Mayores de la Ciudad de México [Mexico City's Institute for the Care of the Elderly]; IMSOL-AM: Inventario Multifacético de Soledad [Multifacet Inventory of Loneliness]; IMSS: Instituto Mexicano del Seguro Social [Mexican Social Security Institute]; INAPAM: Instituto Nacional de las Personas Adultas Mayores [National Institute for Older Adults]; INEGI: Instituto Nacional de Estadística y Geografía [National Institute of Statistics and Geography]; INSEN: Instituto Nacional de la Senectud [National Institute of the Elderly]; ISSSTE: Instituto de Seguridad y Servicios Sociales de los Trabajadores del Estado [Institute for Social Security and Services for State Workers]; RMSEA: Root mean square error of approximation; SRMR: Standardized root mean square residual; TLI: Tucker-Lewis Index; UNAM: Universidad Nacional Autónoma de México [National Autonomous University of Mexico]; WHO: World Health Organization
\end{abstract}

Acknowledgments

The authors want to thank the Dirección General de Asuntos de Personal Académico department at UNAM for the PAPIIT research grant IN308816 "Pobreza como dolor social, su impacto en la salud física y mental en la vejez".

\title{
Authors' contributions
}

Dr. MM was in charge of the project. She wrote the summary, introduction, and most of the discussion section of the manuscript given her research interests and expertise on aging and loneliness. Dr. DL contributed mainly in the writing of the methodology and results sections. He reviewed the manuscript and gave support in the translation of it into English. Dr. LAS contributed in the general editing and proofreading of the revised manuscript. All authors read and approved the final manuscript.

Funding

Funds for this research project came from the Dirección General de Asuntos de Personal Académico department at UNAM.

Availability of data and materials

For regulatory and confidentiality issues, the authors will not share the data. 
Received: 29 November 2018 Accepted: 8 July 2019

Published online: 30 July 2019

\section{References}

Alpass, Fiona, and Stephen Neville. 2003. Loneliness, health and depression in older males. Aging \& Mental Health 7 (3): $212-216$. Andrew, Melissa K., Arnold B. Mitnitski, and Kenneth Rockwood. 2008. Social vulnerability, frailty and mortality in elderly people. PLoS One 3 (5): 1-8.

Bekhet, Abir, and Jaclene Zauszniewski. 2012. Mental health of elders in retirement communities: Is loneliness a key factor? Archives of Psychiatric Nursing 26 (3): 214-224.

Borys, Shelley, and Daniel Pelman. 1985. Gender differences in loneliness. Personality and Social Psychology Bulletin 11 (1): $63-74$

Bronfenbrenner, Urie. 1977. Toward an experimental ecology of human development. American Psychologist 32 (7): 513-530.

Bronfenbrenner, Urie. 1979. The ecology of human development: Experiments by nature and design. Cambridge, Massachusetts: Harvard University Press.

Bronfenbrenner, Urie. 1986. Ecology of the family as a context for human development: Research perspectives. Developmental Psychology 22 (6): 723-742.

Cohen, Sheldon, Tom Kamarck, and Robin Mermelstein. 1983. A global measure of perceived stress. Journal of Health and Social Behavior 24 (4): 385-396.

CONAPO. 2006. "Proyecciones 2005-2050". http://www.alianzacivica.org.mx/guia_transparencia/Files/pdf/desarrollo/14_ PROYECCIONESDELAPOBLACIONDEMEXICO/14_PROYECCIONESDELAPOBLACIONDEMEXICO.pdf

CONEVAL. 2018. "Informe de Evaluación de la Política de Desarrollo social." Recovered October 20th, from https://www. coneval.org.mx/Evaluacion/IEPSM/IEPSM/Documents/IEPDS_2018.pdf

Cutrona, Carolyn, Dan Russell, and Jayne Rose. 1986. Social support and adaptation to stress by the elderly. Psychology and Aging 1 (1): 47-54.

Da Silva Pedro, I., Semiramis M. Melo, and Lucila Castanheira. 2008. Red y Apoyo Social en Enfermería Familiar: Revisión de Conceptos. Revista Latino-Americana Enfermagem 16 (2): 110-117.

Erickson, Erik. 1985. El ciclo vital completado. Barcelona: Paidós.

Guevara, R. Elsa, and María Montero-López Lena. 1994. Diferencias de género en la vivencia de soeldadante el proceso de ruputa marital. Revista de Psicología Contemporánea 1 (2): 16-31.

Holt-Lunstad, Julianne, Timothy B. Smith, and J. Bradley Layton. 2010. Social relationships and mortality risk: A meta-analytic review. PLoS Medicine 7 (7): 1-20.

IAAM. 2017. "Instituto para la Atención de Adultos Mayores de la Ciudad de México." Recovered October 25th, 2018, from: http://www.adultomayor.cdmx.gob.mx

IMSS. 2012. "Norma que establece las disposiciones para operar los programas: envejecimiento activo"http://www.imss.gob. $\mathrm{mx} /$ sites/all/statics/pdf/manualesynormas/3000-001-015.pdf

INEGI. 2018. "Estadísticas a propósito del día internacional de las personas de edad (adultos mayores)" https://www.inegi.org. mx/contenidos/saladeprensa/aproposito/2018/edad2018_nal.pdf

ISSSTE. 2002. "Módulos Gerontológicosy Envajecimiento Saludable." Recovered October 25th, 2018, from http://sgm.issste. gob.mx/medica/envejecimiento_saludable.php

Kim, Erin Hye-Won. 2013. Public support, family support, and life satisfaction of the elderly: Evidence from a new government old-age pension in Korea. Dissertation Abstracts International Section A: Humanities and Social Sciences 73: 8-A.

Krause, Neal. 1987. Life stress, social support, and self-esteem in an elderly population. Psychology and Aging 2 (4): 349-356.

Lau, Sing, E. Gerald, and Gruen. 1992. The social stigma of loneliness: Effect of target person's and perceiver's sex. Personality and Social Psychology Bulletin 18 (2): 82-189.

Lazarus, Richard S., and Susan Folkman. 1986. Estrés y procesos cognitivos. Barcelona: Martínez Roca.

Lipina, Sebastián. 2016. Pobre cerebro: Los efectos de la pobreza sobre el desarrollo cognitivo y emocional, y lo que la neurociencia puede hacer para prevenirlos. Buenos Aires, Argentina: Siglo XXI.

Liu, Yong-Chuang, Li-Na Guo, and Kun Liu. 2016. Relationship between depression level and perceived stress among the elderly in community: Moderating effect and mediating effect. Chinese Mental Health Journal 30 (8): 607-611.

Marin, Merranda, and Charles H. Huber. 2011. Mexican American elderly: Self-reported anxiety and the mediating influence of family protective factors. The Family Journal 19 (1): 63-72.

Marshall, Amanda C., R. Nicholas, Rebecca Segrave Cooper, and Nicolas Geeraert. 2015. The effects of long-term stress exposure on aging cognition: A behavioral and EEG investigation. Neurobiology of Aging 36: 2136-2144.

Montero-López Lena, María. 2003. Significado Psicológico de la Soledad a Través del Ciclo Vital. In Revista Mexicana de Psicología. Memoria en extenso (Núm. Esp.), 80-81.

Montero-López Lena, María, and Gary Evans. 2008. Condiciones ambientales de niños en pobreza provenientes de dos nichos culturales: Ciudad de México y zona rural de New York, USA. Medio ambiente y comportamiento humano 9 (12): 33-45.

Montero-López Lena, María. 1993. Significado psicológico de la soledad en la adolescencia. Revista Mexicana de Psicología Social y Personalidad. 9 (1): 1-12.

Montero-López Lena, María. 1999. Soledad: Desarrollo y Validación de un Inventario Multifacético para su Medición. In (Doctoral Thesis). Universidad Nacional Autónoma de México.

Montero-López Lena, María. 2016a. Costos Psicológicos de Envejecer en Pobreza: Propuesta de un Modelo Correlacional. In UNAM-DGAPA. Technical report. Internal document.

Montero-López Lena, María 2016b. “¿Cómo Convivir con la Soledad?” Dirección General de Divulgación de la Ciencia. UNAM. Recovered October $11^{\text {th }}, 2018$, from: http://www.fundacionunam.org.mx/unam-al-dia/la-unam-te-explica-como-convivircon-la-soledad

Montero-López Lena, María. 2018. Pobreza como Dolor Social, su Impacto sobre la Salud Física y Mental en la Vejez. In UNAM-DGAPA. Technical report. Internal document.

Montero-López Lena, María, and Ricardo Díaz-Castillo. 2017. Sucesos Vitales Estresantes En Dos Grupos De Mujeres Mayores. In Segundo Congreso Internacional Interdisciplinario sobre Vejez y Envejecimiento, 245-246. México: UNAM. 
Montero-López Lena, María, and Armando Rivera-Ledesma. 2009. IMSOL-AM: Escala de Soledad en el Adulto Mayor. In Evaluación en psicogerontología, ed. Ana L. González-Celis, 123-131. México: El Manual Moderno.

Montero-López Lena, María, and Juan J. Sánchez-Sosa. 2001. La Soledad como Fenómeno Psicológico: Un Análisis Conceptual. Salud Mental 24 (1): 19-27.

Rivera-Ledesma, Armando, María Montero-López Lena, and Claudia I. Astudillo-García. 2013. Escala de Soporte Social de Tagaya, Okuno, Tamura y Davis: Propiedades Psicométricas en Adultos Mayores. Diversitas: Perspectiva Psicológica 9 (2): $397-407$.

Rivera-Ledesma, Armando, María Montero-López Lena, and Rosalba Sandoval. 2012. Desajuste Psicológico, Calidad de Vida y Afrontamiento en Pacientes Diabéticos con Insuficiencia Renal Crónica en Diálisis Peritoneal. Salud Mental 35 (4): 329-337.

Samejima, Fumiko. 1997. Graded response model. In Handbook of Modern Item Response Theory, ed. W.J. van der Linden and R.K. Hambleton, 85-100. New York: Springer.

Secretaria de Bienestar. 2019. "Programa para el bienestar de las personas adultas mayores." Recovered April 22 2 , 2019, from: https://www.gob.mx/bienestar/acciones-y-programas/programa-para-el-bienestar-de-las-personas-adultas-mayores

Tagaya, A., S. Okuno, M. Tamura, and A. Davis. 2000. Social support and end-of-life issues for small town Japanese elderly. Nursing and Health Sciences 2: 131-137.

United Nations. 2016. "International Year of Older Persons 1999." Recovered October 30"th 2018 , from: https://www.un.org/ development/desa/ageing/resources/international-year-of-older-persons-1999.html

World Health Organization. 2018. "Depresión, Nota descriptiva" https://www.who.int/topics/depression/es/

Zarit, Steven H., and Allison M. Reamy. 2013. Future directions in family and professional caregiving for the elderly. Gerontology 59 (2): 152-158.

\section{Publisher's Note}

Springer Nature remains neutral with regard to jurisdictional claims in published maps and institutional affiliations.

Submit your manuscript to a SpringerOpen ${ }^{\circ}$ journal and benefit from:

- Convenient online submission

- Rigorous peer review

- Open access: articles freely available online

- High visibility within the field

- Retaining the copyright to your article

Submit your next manuscript at $\boldsymbol{\nabla}$ springeropen.com 